\title{
Social-cognitive Competence, Peer Rejection and Neglect, and Behavioral and Emotional Problems in Middle Childhood
}

\author{
Wendy L. G. Hoglund, Christopher E. Lalonde, and \\ Bonnie J. Leadbeater, University of Victoria
}

\begin{abstract}
This prospective, longitudinal study examines individual differences in two conceptually related but empirically distinct domains of social-cognitive competence (cognitive interpretive understanding and interpersonal perspective co-ordination) as moderators of the relation between peer rejection and neglect and behavioral and emotional problems in grades 2 and 3. As expected, peer rejection and neglect increased risks for behavioral and emotional problems whereas interpretive understanding (understanding of mental states) and perspective co-ordination (awareness of others' emotions and motives) reduced risks for aggressive, disruptive, inattentive, and anxious, sad, withdrawn behaviors. Assumptions that awareness of others' perspectives bestows consistent benefits for children experiencing peer problems were challenged. Unexpectedly, rejection and neglect increased risks for behavioral and emotional problems for children who demonstrated average and high levels of perspective co-ordination. More advanced perspective co-ordination may heighten children's sensitivity to peer relationship problems and result in general maladjustment, both concurrently and over time. Less advanced perspective co-ordination may also be responsible for the 'optimistic bias' that has been noted in aggressive children.
\end{abstract}

Keywords: social cognition; behavioral and emotional problems; peer rejection; middle childhood

Peer rejection and neglect are interpersonal stressors that characterize the relationship between a particular child and her or his peer group. Findings converge across several studies in documenting that peer rejection and neglect can give rise to a constellation of behavioral (aggressive, disruptive, unco-operative behaviors) and emotional (sadness, anxiety, withdrawal) problems in middle childhood (Bierman, 2004; Newcomb, Bukowski, \& Pattee, 1993). However, not all rejected or neglected children show these problems (LaFontana \& Cillessen, 2002; Mostow, Izard, Fine, \& Trentacosta, 2002). Accumulating evidence suggests that social-cognitive abilities that enable children to understand multiple perspectives and attend to multiple views in interpersonal conflicts can shape children's concurrent and ongoing behavioral and emotional

Correspondence should be addressed to Wendy Hoglund, Department of Applied Psychology, New York University, East Building 5th Floor, 239 Greene Street, New York, NY 10003. Email: whoglund@nyu.edu 


\section{Wendy L. G. Hoglund, Christopher E. Lalonde and Bonnie J. Leadbeater}

problems in response to peer problems (Badeness, Estevan, \& Bacete, 2000; Dekovic \& Gerris, 1994; Dodge et al., 2003; Dunn \& Cutting, 1999; Hoglund \& Leadbeater, 2007). The current study examines individual differences in two conceptually related but empirically distinct forms of social-cognitive competence (cognitive interpretive understanding, interpersonal perspective co-ordination) as moderators of the relation between peer rejection and neglect and behavioral and emotional problems in middle childhood.

Social-cognitive competence is a multifaceted construct that includes both the cognitive ability to understand that different people may hold unique perceptions of the same information (Chandler \& Lalonde, 1996), and also the social or interpersonal capacity to consider and co-ordinate other people's perspectives of an event with one's own view (Selman, 1980, 2003). Social-cognitive competence develops over time, in part through social experiences with peers, and prepares children for challenging social interactions because it enables them to forecast and understand how others might interpret and react to social events (Piaget, 1965; Selman, 2003). Accordingly, children who show a greater awareness of peers' emotional and mental states may be better able to resolve conflicts in ways that foster long-term relationships, relative to children who show poorer social-cognitive competence (Leadbeater, Ohan, \& Hoglund, 2006; Yeates, Schultz, \& Selman, 1991). Similarly, individual differences in the socialcognitive competence of children who are rejected or neglected by peers may affect their levels of behavioral and emotional problems. For instance, rejected or neglected children who can anticipate and prevent future negative peer interactions may inhibit actions that could encourage further peer dislike or dismissal such as crying easily, reticence, or retaliatory aggression (Dekovic \& Gerris, 1994; Dodge et al., 2003; Hoglund \& Leadbeater, 2007). Alternatively, sophisticated social-cognitive abilities may interfere with rejected or neglected children's ability to limit aggressive, disruptive or anxious, withdrawn behaviors because a keen ability to recognize others' perspectives intensifies children's sensitivity to peer negativity (Cutting \& Dunn, 2002). We turn now to a review of the literature on peer rejection and neglect, social-cognitive competence, and behavioral and emotional problems in middle childhood.

\section{Peer Rejection and Neglect and Behavioral and Emotional Problems in Middle Childhood}

Peer rejection and neglect are markers of children's acceptance in the peer group. Rejected children are overtly disliked by their peer group whereas neglected children are ignored and avoided by their peer group (Bierman, 2004; Newcomb et al., 1993). Still, both rejection and neglect are social processes that actively exclude a child from the peer group. Both have also been identified as antecedents and consequences of behavioral and emotional problems, with somewhat higher associations between rejection and aggression than between neglect and aggression (Bierman, 2004; Newcomb et al., 1993). Early childhood displays of aggressive, demanding behaviors heighten risks for later peer rejection in middle childhood (Dodge et al., 2003). Other longitudinal evidence also suggests that aggressive and anxious, avoidant behaviors operate additively with peer rejection to elevate risks for maladjustment throughout middle childhood (Ladd, 2006). Such peer problems can limit children's opportunities to interact with the peer group because of the stigma that active peer dislike and avoidance carries. Moreover, once children are disregarded by a majority of the peer group, 
prosocial peers and peers in general treat them more negatively and isolate them more often, contributing to ongoing risks for maladjustment (Buhs \& Ladd, 2001). Peer rejection and neglect may also shape children's negative cognitions and expectations about future peer interactions and sustain the developmental course of behavioral and emotional problems (Ladd \& Troop-Gordon, 2003; Rudolph, Hammen, \& Burge, 1997). We extend this line of inquiry by examining individual differences in socialcognitive competence as a moderator of the consequences of peer rejection and neglect on behavioral and emotional problems in middle childhood.

\section{Theoretical Perspectives on Social-cognitive Competence in Middle Childhood}

The ability to understand that different people may hold unique cognitive interpretations of the same ambiguous information commonly unfolds in middle childhood (Chandler \& Lalonde, 1996). Similarly, the social capacity to disentangle one's own perspective from that of another in interpersonal interactions also matures in middle childhood (Selman, 1980). These cognitive and interpersonal components of socialcognitive competence have both been linked negatively to peer rejection and neglect and also to behavioral and emotional problems in some studies (Badeness et al., 2000; Dunn \& Cutting, 1999; Hoglund \& Leadbeater, 2007; Hughes \& Dunn, 1998; Leadbeater et al., 2006; Watson, Nixon, Wilson, \& Capage, 1999), but not in others (Bosacki \& Astington, 1999; Kauklainen et al., 1999; Slaughter, Dennis, \& Pritchard, 2002; Sutton, Smith, \& Swettenham, 1999). These inconsistent findings may be in part because research concerning these distinct social-cognitive components has been conducted independently, even though they overlap theoretically (Raver \& Leadbeater, 1993). This study assesses how individual differences in each of these social-cognitive components contribute uniquely to behavioral and emotional problems and influence the relation between peer rejection and neglect and these problems in middle childhood.

Cognitive interpretive understanding has been examined by cognitive interpretive theory of mind tasks with ambiguous, restricted-view drawings designed to tap children's understanding of others' cognitions about ambiguous information (e.g., Lalonde \& Chandler, 2002; Pillow \& Henrichon, 1996). According to Chandler and colleagues' interpretive theory of mind (Carpendale \& Chandler, 1996; Chandler \& Lalonde, 1996), interpretive understanding is the cognitive appreciation that the mind itself can construct the contents of people's mental states and that reality can be both interpreted and misinterpreted. Interpretive understanding calls for a more sophisticated cognitive flexibility than the false belief understanding assessed in most theory of mind studies because it requires children not only to inhibit their own privileged knowledge of an event, but also to recognize that different people may hold unique and possibly opposing interpretations of the exact same event. Interpretive understanding is thought to enhance children's skills in relating to others and resolving conflicts because understanding the possibility of multiple viewpoints as legitimate interpretations of social reality can diminish risks for social misunderstandings (Chandler \& Lalonde, 1996). This more sophisticated interpretive understanding may also reduce risks for behavioral problems among rejected or neglected children because they can recognize the possible ambiguity in the meaning of their own and others' behaviors and consequently limit retaliatory aggression related to social misinterpretations or hostile attributional biases (Crick \& Dodge, 1994). Similarly, these children may show fewer emotional problems because they can limit emotional distress that results from 
preoccupation with misinterpreted peer interactions (Rudolph \& Clarke, 2001). On the other hand, a keen ability to recognize the possibility of multiple views may provoke rejected or neglected children to retaliate aggressively or worry excessively because they are better able to recognize peers' antagonistic intentions and behaviors in ambiguous social interactions (Kauklainen et al., 1999; Sutton et al., 1999).

Interpersonal perspective co-ordination is theoretically related to cognitive interpretive understanding of multiple viewpoints. Perspective co-ordination has typically been assessed using hypothetical social vignettes designed to elicit children's competence in identifying the emotional states and motives of multiple others (e.g., Erdley \& Asher, 1996; Leadbeater et al., 2006; Yeates et al., 1991). According to Selman's $(1980,2003)$ theory of interpersonal understanding, interpersonal perspective co-ordination refers to the cognitive awareness of the internal thoughts, motives, and feelings of the self and others in social interactions. By middle childhood, most children can appreciate that motives underlie behaviors and can reflect on others' thoughts and feelings and recognize that others can do the same. However, perspective co-ordination is initially a step-by-step process and resolutions to interpersonal conflicts satisfy the needs of the self and of others sequentially, with a focus on immediate, short-term solutions. An increased ability to balance the perspectives of the self and of others, simultaneously, enhances children's ability to resolve conflicts in ways that address the needs of both the self and others in the long term (Selman, 2003). Consistent with this, more advanced interpersonal perspective co-ordination may enable rejected or neglected children to limit retaliatory aggression because they anticipate peer responses and focus on future-oriented collaborative solutions that can maintain or enhance their relationships. Similarly, these children may show fewer emotional problems because they proactively manage problematic interactions and limit preoccupation with short-term peer problems (Hoglund \& Leadbeater, 2007; Leadbeater et al., 2006; Yeates et al., 1991). Alternatively, more skillful perspective co-ordination may increase poorly accepted children's risks for maladjustment because their ability to gauge peers' emotions and motives in social interactions increases their hypervigilance for future negative interactions (Cutting \& Dunn, 2002)

\section{Social-cognitive Competence and Behavioral and Emotional Problems in Middle Childhood}

Research indicates that subscribing to an interpretive theory of mind matures at about six to eight years of age (Carpendale \& Chandler, 1996; Lalonde \& Chandler, 2002; Pillow \& Henrichon, 1996). Lalonde and Chandler (2002) examined the emergence of interpretive understanding using ambiguous, restricted-view line drawings. Children aged five, six, and seven years were shown a series of full line drawings (e.g., a ship and a witch in water) and ambiguous, restricted views of the line drawings (e.g., the tip of the ship's bow and witch's hat). (See Appendix A.) Children were asked how two different viewers (puppet characters who had not seen the full line drawings) would interpret the ambiguous, restricted views. To pass the interpretive tasks, children were required to estimate that the two puppets would interpret the ambiguous stimuli differently from each other and from the child's own privileged knowledge of the full picture. Sevenyear-old children showed reliably better interpretive understanding than the five- and six-year-old children, but were accurate in only about 85 percent of the trials. Similarly, in a study of five- to eight-year-old children, Carpendale and Chandler (1996) reported that only 67 percent of the eight-year-old children were able to predict how a third naive 
viewer might interpret other ambiguous stimuli. These findings demonstrate individual differences in interpretive understanding in middle childhood and suggest that even at seven to eight years of age, individual variability should be expected.

Several studies have found that a more sophisticated understanding of mental states relates positively to social adjustment in early to middle childhood, such as co-operative peer play and following rules or directions (Badeness et al., 2000; Cassidy, Werner, Rourke, Zubernis, \& Balaraman, 2003; Hughes \& Dunn, 1998; Jenkins \& Astington, 2000; Slaughter et al., 2002; Watson et al., 1999). For instance, Watson et al. reported that preschoolers who demonstrated a more competent understanding of mental states were rated higher by teachers on social adjustment. However, most studies of children's understanding of mental states have been cross-sectional, have focused on social adjustment, and have used false belief theory of mind tasks. Few studies have assessed how such an understanding of mental states relates to children's behavioral and emotional problems using more cognitively complex interpretive theory of minds tasks. A more advanced interpretive understanding may enable children to consistently distinguish their own and their peers' interpretations of negative interactions and allow them to reduce the salience of rejection and neglect by some peers, lessening risks for maladjustment.

Cross-sectional and longitudinal research indicates that children who demonstrate more mature interpersonal perspective co-ordination generally show fewer behavioral and emotional problems and better social adjustment in early to late childhood than those who show less skillful perspective co-ordination (Bosacki \& Astington, 1999; Dunn \& Cutting, 1999; Erdley \& Asher, 1996; Hoglund \& Leadbeater, 2007; Leadbeater et al., 2006). For instance, greater perspective co-ordination, assessed from responses to questionnaires and vignettes, has been linked to lower levels of aggression in kindergarten to grade 4 (Fitzgerald \& White, 2003) and to less aggression and depression in grades 6 and 7 (Hoglund \& Leadbeater, 2007). Perspective co-ordination also related positively to co-operative play with peers in preschool (Dunn \& Cutting, 1999) and to social adjustment in grades 1-3 (Leadbeater et al., 2006) and in grades 4, 6, 8, and 12 (Schultz, Selman, \& LaRusso, 2004).

Nonetheless, research linking interpretive understanding and perspective co-ordination to behavioral and emotional problems and social adjustment is mixed (Bosacki \& Astington, 1999; Kauklainen et al., 1999; Slaughter et al., 2002; Sutton et al., 1999). For instance, drawing from theory on both interpretive understanding and perspective co-ordination, Bosacki and Astington (1999) found that children who gave more cognitively complex answers about the characters in interpersonal vignettes (responses that referred to the characters' emotions and motives) showed better peerrated but not teacher-rated social adjustment. Explanations for the mixed findings for interpretive understanding and perspective co-ordination research may relate to their unique contribution to behavioral and emotional problems and social adjustment and to their unique relation to children's peer problems in middle childhood.

\section{Social-cognitive Competence and Peer Rejection and Neglect in Middle Childhood}

Relations between aspects of social-cognitive competence and peer rejection and neglect in early to middle childhood have been demonstrated in both cross-sectional and longitudinal studies (Dodge et al., 2003; Ladd \& Troop-Gordon, 2003; Mostow et al., 2002; Rudolph et al., 1997; Slaughter et al., 2002; Watson et al., 1999; Yeates 


\section{Wendy L. G. Hoglund, Christopher E. Lalonde and Bonnie J. Leadbeater}

et al., 1991). For instance, Yeates et al. (1991) found that higher levels of teacher-rated perspective co-ordination and children's greater endorsement of competent conflictresolution strategies related positively to peer-rated acceptance (popularity) in grades 3-5. Social-cognitive competence also correlates negatively with peer rejection in middle childhood (Dodge et al., 2003; Ladd \& Troop-Gordon, 2003; Rudolph et al., 1997; Slaughter et al., 2002). For instance, research with children in grades 1, 3, and 5 found that competent understanding of others' mental and emotional states was higher in popular than rejected children, especially among older children (Dekovic \& Gerris, 1994).

However, other studies have not found links between cognitive and interpersonal aspects of social-cognitive competence and peer rejection or neglect (Astington \& Jenkins, 1995; Badeness et al., 2000; Bosacki \& Astington, 1999; Kauklainen et al., 1999; Sutton et al., 1999). For instance, Badeness et al. found few differences in performance on mental state understanding tasks among popular, average-status, and rejected preschool children. Research with preadolescents also found no relation between perspective co-ordination and peer acceptance (Bosacki \& Astington, 1999). In addition, Sutton et al.'s (1999) research with 7- to 10-year-old children found that physically aggressive 'bullies' showed unexpectedly higher levels of understanding of others' mental and emotional states than children who supported the bully or defended the victim and children who were the victims. Such mixed findings draw attention to the potentially differential benefits and costs of more advanced cognitive and interpersonal domains of social-cognitive competence for children who experience peer rejection or neglect.

How individual differences in both cognitive and interpersonal aspects of socialcognitive competence influence the association between peer problems and behavioral and emotional problems is not well understood. We propose that children who can appreciate that others' cognitive interpretations of a social event might legitimately differ from their own and who can balance the interpersonal perspectives of the self and others in social encounters may be better able to forecast others' emotions and intentions in social interactions and successfully prevent or proactively manage peer rejection or neglect. On the other hand, skillful understanding of others' interpretations or perspectives may actually heighten children's sensitivity to peer rejection or neglect and could serve to increase risks for problems (Cutting \& Dunn, 2002; Rudolph \& Clarke, 2001; Rudolph et al., 1997). To inform prevention programs directed at enhancing peer relationships, it is critical to understand the role of social-cognitive competence in children's ability to manage peer problems.

\section{The Current Study}

In sum, the purpose of the current study is to examine individual differences in two conceptually related but empirically distinct domains of social-cognitive competence (cognitive interpretive understanding and interpersonal perspective co-ordination) as moderators of the concurrent and prospective relations between peer rejection and neglect and behavioral (aggressive, unco-operative, disruptive behaviors) and emotional (anxiety, sadness, fearfulness, withdrawal) problems in middle childhood. We assess social-cognitive competence using a cognitive interpretive task (ambiguous, restricted-view drawings to estimate insight into others' cognitions) and an interpersonal perspective task (vignettes to gauge awareness of others' emotional states and motives). Cognitive interpersonal understanding and interpersonal perspective 
co-ordination were both expected to (1) contribute uniquely to fewer behavioral and emotional problems, both concurrently and over time, and (2) also moderate the effects of peer rejection and neglect on concurrent and prospective levels of behavioral and emotional problems in middle childhood.

\section{Methods}

\section{Participants}

Participants included 114 children first assessed in the spring of grade 1 (mean age six years and three months; 50 percent girls) and follow-up included all 114 children in the spring of grade 2 (2002) and 100 children in the spring of grade 3 (2003). Attrition was due to children moving to different schools. All children had parental consent to participate (consent rate was 64 percent). Parent reports indicated that 34.7 percent of the children lived in a household with a total annual income of less than $\$ 30,000$ (range $=$ less than $\$ 8,500$ to $\$ 50,000$ or more per annum), 70.8 percent lived in a two-parent household, and 70 percent lived in a household where English was the only language spoken. Children's ethnicity or race was 73 percent Canadian and European White, 12.3 percent South East and East Asian, 9.6 percent Aboriginal, 1.5 percent Other (e.g., Hispanic, Caribbean), and 3.6 percent reported no ethnicity or race.

\section{Procedure}

Data assessing behavioral and emotional problems were collected at baseline in the spring of grade 1 and at both follow-ups in the spring of grades 2 and 3. Data assessing children's social-cognitive competence and peer acceptance were collected in grade 2. Parents who gave consent for their child's participation completed questionnaires assessing family demographics at home and returned these to their child's teacher in a sealed envelope. In grades 1, 2, and 3, different teachers completed questionnaires rating the behavioral and emotional problems of each child in their class with consent to participate. Grade 2 teachers also rated children's peer rejection and neglect. Teachers completed these forms when the children's questionnaires were administered. In grade 2, children completed two tasks assessing their social-cognitive competence during class time. The social-cognitive tasks and corresponding questions were read aloud to the children in class groups of 9-20 children by the first author. This reduced reading demands and ensured that all children followed along at approximately the same rate. Research assistant helpers, paired with one or two children, assisted individual children in confidentially answering the questions for each social-cognitive task and when necessary probed children individually for clarification. Children individually and confidentially whispered their answers to their helpers, who then recorded the children's answers verbatim. Research assistants sat between the two children they assisted to ensure that the children could not see each other's answers or hear other children's responses. Research assistants alternated which child was the first respondent for each question.

\section{Measures}

Basic psychometric properties and mean levels of each measure are shown in the bottom of Table 1. 
8 Wendy L. G. Hoglund, Christopher E. Lalonde and Bonnie J. Leadbeater

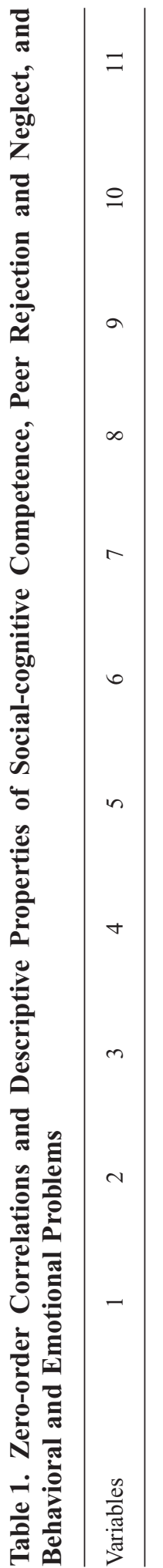

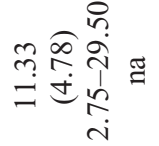

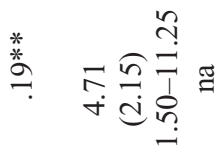

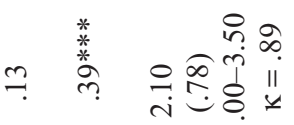

$$
\begin{aligned}
& \text { 苂 }
\end{aligned}
$$

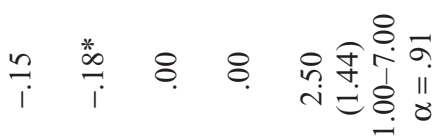

$$
\begin{aligned}
& \text { * }
\end{aligned}
$$

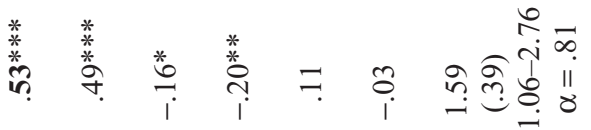

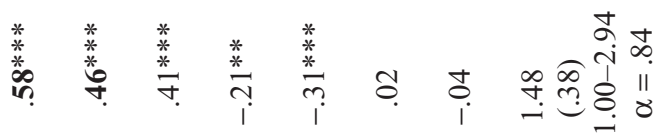

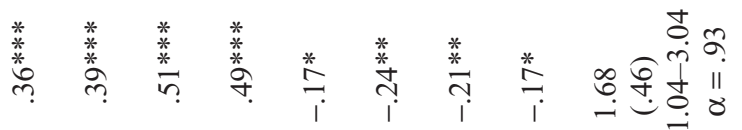

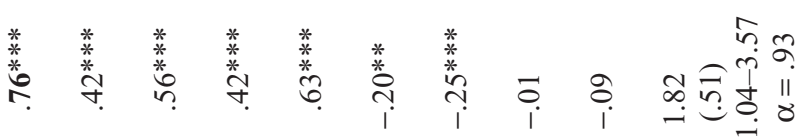

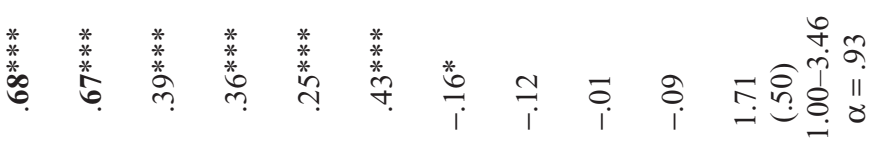

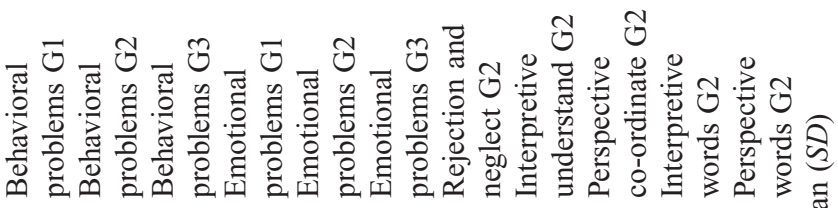

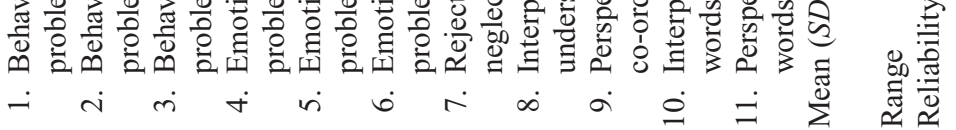

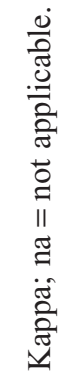

$$
\begin{aligned}
& \text { 范 } \\
& \underline{11} \\
& \frac{\tilde{\Xi}}{\tilde{\Xi}} \\
& \text { 욜 }
\end{aligned}
$$

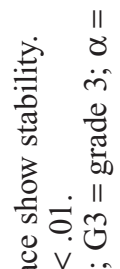

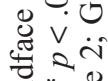

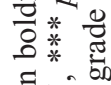

$$
\begin{aligned}
& \text { ज. }
\end{aligned}
$$

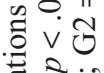

$$
\begin{aligned}
& \text { 类 } * \frac{1}{0} \\
& \text { ర유. }
\end{aligned}
$$

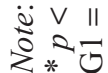


Behavioral and emotional problems were assessed from teacher reports on the early school behavior rating scale (Caldwell \& Pianta, 1991) in grades 1, 2, and 3. This scale measures behavioral problems from 9 items (e.g., aggression, temper tantrums, hyperactivity, inattentiveness), emotional problems from 17 items (e.g., anxiety, shyness, sadness, withdrawal), and social adjustment on 14 items (e.g., co-operative with peers and adults, follows directions, adheres to rules). Items were rated on a 4-point scale ( 1 = hardly ever, 4 = almost always). For the current study, behavioral problems were computed as the average of the 9 behavioral and 14 social items (reverse scored) as these scales were highly and negatively correlated at each grade ( $r \mathrm{~s}=-.61$ to -.69 ) and findings for the regression analyses were highly consistent for these scales. Emotional problems were computed as the average of the 17 emotional items. Grade 1 levels of behavioral and emotional problems are included as control variables in the regression analyses.

Peer rejection and neglect were assessed from teacher reports of rejection (overt dislike) and neglect (ignored or avoided) by peers on the teacher sociometric rating form (Rudolph et al., 1997) in grade 2. This measure contains three items that assess the degree to which children are rejected/disliked, neglected/ignored, or popular among peers. Each item is rated on a 7 -point scale $(1=$ not at all $\mathrm{rejected} /$ neglected/popular, $7=$ extremely rejected/neglected/popular). Only the rejection and neglect items are used for the current analyses given the focus on peer problems. Rejection and neglect were both negatively correlated with popularity $(r \mathrm{~s}=-.63$ and -.61 , respectively). Rejection and neglect correlated highly $(r=.91)$ and were averaged to create one indicator of low peer acceptance. Although peer sociometric ratings are generally preferred, teacher ratings have demonstrated adequate reliability (Rudolph et al., 1997) and convergence across teachers over time (Gazelle, 2006).

Cognitive interpretive understanding was assessed from children's self-reports on an interpretive theory of mind task in grade 2. This measure uses two ambiguous, restricted-view line drawings called 'droodles' (Lalonde \& Chandler, 2002; Price, 1953). (See Appendix A.) The full view of a line drawing (a ship and a witch; an elephant with its trunk sucking up a round object) was covered with a cardboard overlay. The overlay had a small viewing window that, when opened, revealed an ambiguous, restricted view of the full drawing (the tip of the ship bow and witch's hat; the elephant's trunk and ball). Children were shown the full view of the first droodle and asked 'What is this a picture of?' This question ensured that children focused on the salient components of the picture (i.e., the ship's bow and witch's hat; the elephant's trunk and ball). Children individually whispered their answers to their research assistant helper, who recorded their answers verbatim. The cardboard overlay was then closed. Next, children were told that 'Sam is a child who has never seen this picture before (a cartoon image of Sam is shown). We are going to show Sam this picture, but we are going to show it to Sam like this...', and the window was opened to reveal the ambiguous, restricted-view drawing. Lastly, children were asked, 'What will Sam say this is?' and whispered their answers to their helper. This protocol was then repeated using a second character (Casey) and then repeated with the second droodle picture. The presentation order of the droodles was counterbalanced.

Children's answers were coded according to standard false belief and interpretive scoring. For each droodle, children were credited with an interpretive understanding score of 1 if they gave different false belief answers for each character that also differed from the child's own privileged knowledge of the full picture (e.g., the answer for one 
character was two arrows and the answer for the second character was a triangle). Children whose answers were the same for both characters or the child's own knowledge received a score of 0 . Interpretive scores were summed across the two droodles and classified as low $=0$ (no understanding; $\mathrm{N}=30,26.3$ percent), average $=1$ (transitory understanding; $\mathrm{N}=42,36.8$ percent), and high $=2$ (competent understanding; $\mathrm{N}=42,36.8$ percent). Overall, approximately 75 percent of the seven-year-olds passed at least one interpretive task, converging with findings from Lalonde and Chandler (2002). Answers were coded independently by two trained research assistants. Average Cohen's $\kappa$ was.81 (range $=.77$ to .86 ), indicating good inter-rater reliability. Disagreements were resolved through discussion. There was modest variability in interpretive understanding within classrooms as indicated by the moderate intra-class correlation (ICC) coefficient of .113, a measure of the interdependence of children's answers within classrooms relative to children in different classrooms.

Interpersonal perspective co-ordination was assessed from children's self-reports in grade 2 using two hypothetical peer victimization vignettes (see Appendix B; Selman, 1980). The vignettes were read aloud twice to ensure that children understood the main conflict. Following each question, children individually and confidentially whispered their answers to their research assistant helper, who recorded their answers verbatim. When necessary, research assistants probed children individually to clarify their answer. Children were first asked, 'What is the problem in this story?' (follow-up probe: 'What is happening in this story?'), to assess children's perspective of who was responsible for the problem and whose perspectives were considered (no character, either the victim or aggressor, or both characters). Next, children were asked, 'How do you think [the main characters] could work things out?' (follow-up probe: 'Is there anything else that could help [the main characters] work things out?'), to assess children's solution to the problem. Lastly, children were asked, 'Why is that a good way to solve the problem?' (follow-up probe: 'How would that stop the problem from happening again on another day?'), to assess who children perceived would benefit from solutions they generated and whose perspectives were considered (no character, either the victim or aggressor, or both characters). The presentation order of the vignettes was counterbalanced and children working with a research assistant alternated being the first respondent for each question.

Similar to past assessments of perspective co-ordination (Bosacki \& Astington, 1999; Dunn \& Cutting, 1999), children's answers to the two questions regarding who was responsible for the problem and who benefited from the solution were coded whether they referred to the victim's and/or the aggressor's emotional states $(0=$ no, $1=$ yes; e.g., feelings, likes, preferences $)$ and motives or beliefs $(0=$ no, $1=$ yes; e.g., thoughts, intentions, desires).Whose emotional states and motives were considered was also rated $(0=$ no character, $1=$ aggressor only, $2=$ victim only, and $3=$ both characters). Responses that referred to the aggressor's emotions and/or motives only did not demonstrate insight into the important problem that someone was getting hurt and were credited with a lower score. Responses that referred to both characters' emotions and/or motives were considered the most complex and were credited with the highest score. For example, 'Taylor (the aggressor) wants to join in the game because she feels left out' was scored as 1 for emotional states ('feels left out') and 1 for considering the aggressor's (Taylor) emotions only, and 1 for motives ('wants') and 1 for considering the aggressor's motives only, for a total score of 4; 'Erin (the victim) was probably really lonely and she wanted to make friends' was scored as 1 for 
emotional states ('lonely') and 2 for considering the victim's (Erin) emotions, and 1 for motives ('wanted') and 2 for considering the victim's motives, for a total score of 6 . Scores were summed for a total possible range of $0-8$ per vignette and averaged across the two vignettes. Higher scores reflected greater perspective complexity of children's answers. Children's answers were coded independently by two trained research assistants. Average Cohen's $\kappa=.89$ (range $=.76-1.00$ ), indicating high inter-rater reliability. Disagreements were resolved through discussion. There was substantial variability in perspective co-ordination within classrooms relative to between classrooms as indicated by a low ICC (.004).

Average word count was computed for the cognitive interpretive tasks and for the interpersonal perspective vignettes and used to control for potential biases in these social-cognitive assessments related to verbal fluency. Total word count was calculated for each cognitive interpretive task and then averaged across the two cognitive tasks for an average interpretive word count. Total word count was also computed for each interpersonal perspective vignette and then averaged across the two vignettes for an average perspective word count. Interpretive understanding was unrelated to average interpretive word count $(r=.12$, NS), suggesting that verbal fluency did not significantly relate to children's ability to demonstrate interpretive understanding. Alternatively, perspective co-ordination correlated moderately with average perspective word count $(r=.39, p<.01)$, indicating that verbal fluency related moderately to children's ability to demonstrate better perspective co-ordination. The ICCs for interpretive word count (.082) and perspective word count (.005) indicated substantial variability in word count within classrooms relative to between classrooms but more similarity within classrooms for interpretive explanations as compared to perspective word count.

\section{Results}

Findings are presented in two sections. Firstly, descriptive data for social-cognitive competence, peer rejection and neglect, and behavioral and emotional problems, and inter-correlations among these variables are shown. Secondly, hierarchical regression equations examining the moderating effects of social-cognitive competence on the relations between peer rejection and neglect and concurrent and prospective levels of behavioral and emotional problems are presented separately.

\section{Descriptive Analyses}

As shown in Table 1, average levels of peer rejection and neglect and behavioral and emotional problems indicated low base rates of these problems. The average interpretive value indicated that most children showed a transitory understanding of interpretation. Similarly, the average perspective level indicated that most children showed a moderate awareness of multiple emotional states and motives. Few mean-level differences were found between girls and boys. Consistent with past research (Bosacki \& Astington, 1999; Schultz et al., 2004), girls showed a moderately better perspective co-ordination than boys; $F(1,112)=5.67, p<.05, \eta=.05$; mean $(S D)=2.27(.77)$ for girls and $1.93(.76)$ for boys. Girls also used slightly more words on average in their perspective responses than boys did; $F(1,112)=3.57, p=.06, \eta=.03$; mean $(S D)=12.17$ (4.49) for girls and 10.50 (4.97) for boys. Girls also showed modestly higher levels of interpretive understanding and peer rejection and neglect than boys, but these differences were not significant. Boys showed more behavioral problems than 
girls, but this difference was significant at baseline only; $F(1,107)=3.83, p<.05$, $\eta=.04$; mean $(S D)=1.61$ (.44) for girls and 1.80 (.55) for boys. Levels of emotional problems were similar across girls and boys at each grade.

Inter-correlations among both domains of social-cognitive competence, peer rejection and neglect, and behavioral and emotional problems are also shown in Table 1. As expected, interpretive understanding and perspective co-ordination were significantly and positively associated $(r=.32)$, but with only about 10 percent of the variance shared between these constructs. Interpretive understanding and perspective co-ordination both correlated significantly with fewer behavioral problems in grades 1,2 , and 3 (with the exception of grade 1 behavioral problems for perspective co-ordination) and emotional problems in grades 1 and 2. Interpretive understanding and perspective co-ordination were also negatively associated with peer rejection and neglect, but only the association with perspective co-ordination approached significance $(p<.10)$. Peer rejection and neglect correlated significantly with higher levels of behavioral and emotional problems at each grade. Behavioral and emotional problems correlated moderately in the expected directions, concurrently and over time.

\section{Effects of Social-cognitive Competence and Peer Rejection and Neglect on Behavioral and Emotional Problems}

Hierarchical multiple regression models examined the unique influence of both constructs of social-cognitive competence (interpretive understanding and perspective co-ordination) and peer rejection and neglect on concurrent and prospective levels of behavioral and emotional problems, and the moderating effects of both interpretive understanding and perspective co-ordination on the associations between rejection and neglect and these problems. In each regression equation, baseline (grade 1) levels of behavioral or emotional problems and also social-cognitive word counts were entered in step 1 as controls. Grade 2 levels of peer rejection and neglect and social-cognitive competence were entered second, and the interactions of interpretive understanding and perspective co-ordination with rejection and neglect were entered last. Significant interactions were probed by examining the slope of the relation between rejection and neglect and behavioral or emotional problems at low, average, and high levels of social-cognitive competence (Aiken \& West, 1991). Gender is not included in the regression equations because the main effects for gender and interactions between social-cognitive competence and gender were not significant in any of the equations, and estimates for equations that included gender were identical to the estimates presented. Interactions between social-cognitive competence and word counts are also not included as they were not significant in any equation.

Behavioral Problems. As shown in Table 2, the regression equations examining the unique influence of both domains of social-cognitive competence (interpretive understanding and perspective co-ordination) and peer rejection and neglect on concurrent and prospective levels of behavioral problems, controlling for baseline problems and word count, were significant and explained 64 and 57 percent of the variance in concurrent and prospective levels of behavioral problems, respectively. Findings were generally consistent, with the exception that interpretive word count was associated with significantly fewer prospective behavioral problems. This suggests that verbal fluency in grade 2 may be an indicator of grade 3 aggressive, disruptive, and inattentive behavior. Peer rejection and neglect were associated with significantly more behavioral 


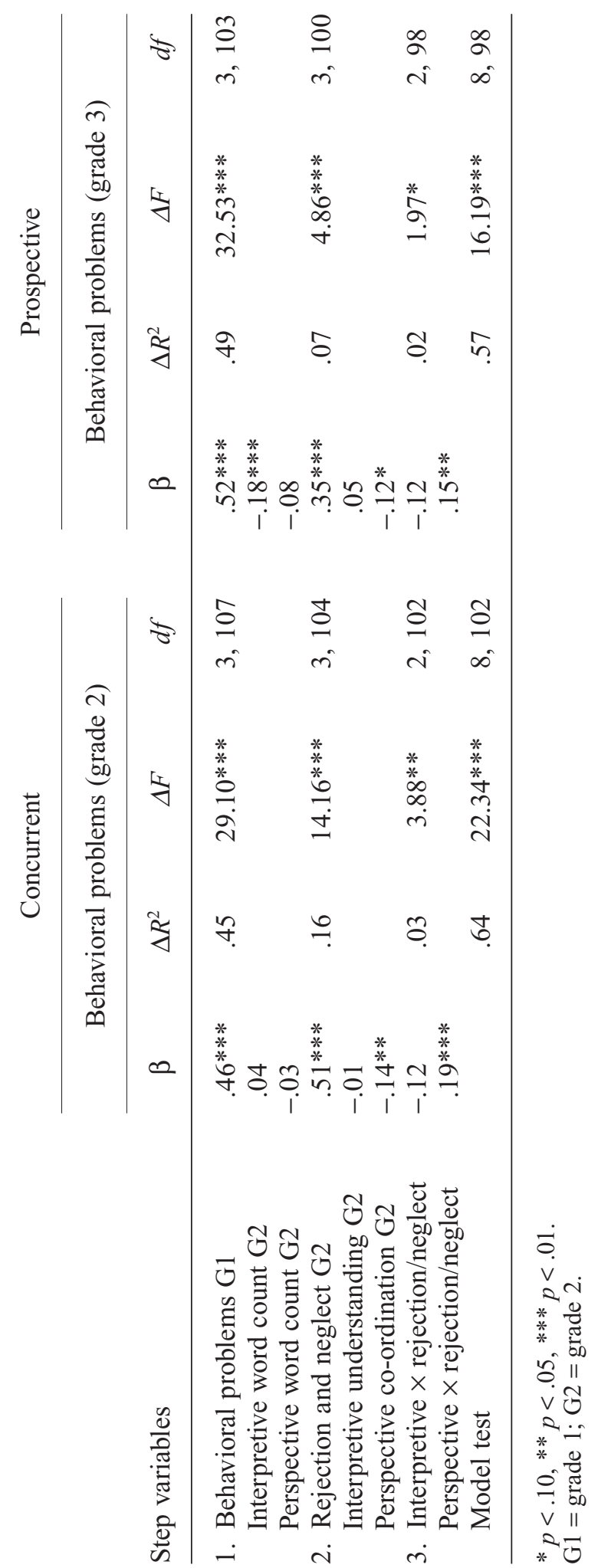




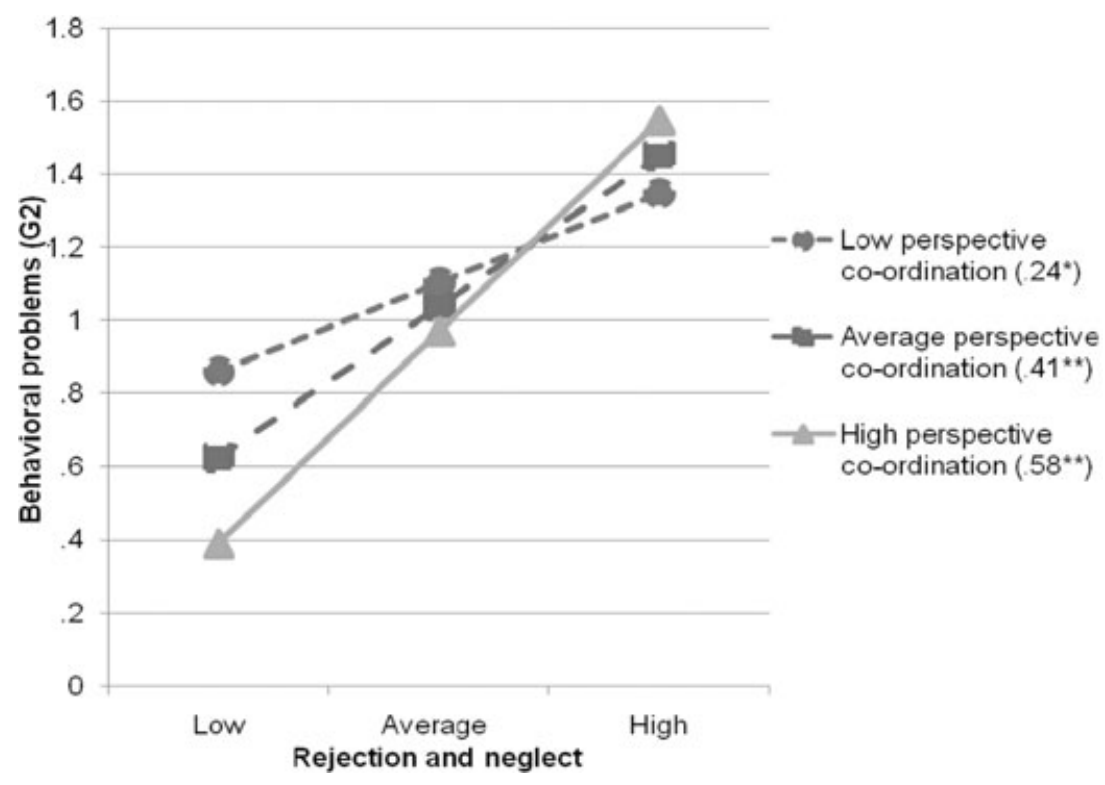

Figure 1. The Relation between Peer Rejection and Neglect and Concurrent Behavioral Problems as a Function of Interpersonal Perspective Co-ordination.

Note: $\mathrm{G} 2=$ grade 2 . Numbers in parentheses are $\beta$ values for slopes $(* p<.05$, $* * p<.01)$. Slope was significantly different from zero for low $(t[102]=2.69, p<.05)$, average $(t[102]=6.12, p<.01)$, and high $(t[102]=6.08, p<.01)$ levels of interpersonal perspective co-ordination.

problems concurrently and prospectively, even after adjusting for baseline problems. More competent perspective co-ordination (but not interpretive understanding) contributed to significantly fewer behavioral problems, both concurrently and over time (although the prospective influence was at the trend level only $p<.10$ ). Consistent with expectations, these findings suggest that peer rejection and neglect elevate risks for behavioral problems whereas more competent perspective co-ordination lessens risks for aggressive, disruptive, rule-breaking, and inattentive behaviors.

The interaction between perspective co-ordination (but not interpretive understanding) and rejection and neglect was also significant for both concurrent and prospective levels of behavioral problems, supporting the hypothesis that perspective co-ordination and peer rejection and neglect contribute both independently and jointly to behavioral adjustment in the short and long term. Interactions were examined by assessing the slope of the relation between rejection and neglect and behavioral problems at low, average, and high levels of perspective co-ordination. Unexpectedly, peer rejection and neglect were associated with higher concurrent levels of behavioral problems for children at all levels of perspective co-ordination, but the slope was steeper at average and high levels relative to low levels of perspective co-ordination (see Figure 1). Peer rejection and neglect also contributed to higher levels of prospective behavioral problems for children who showed average or high (but not low) levels of perspective co-ordination (see Figure 2). These findings lend support to the proposition that in the context of peer rejection or neglect, children with more advanced perspective 


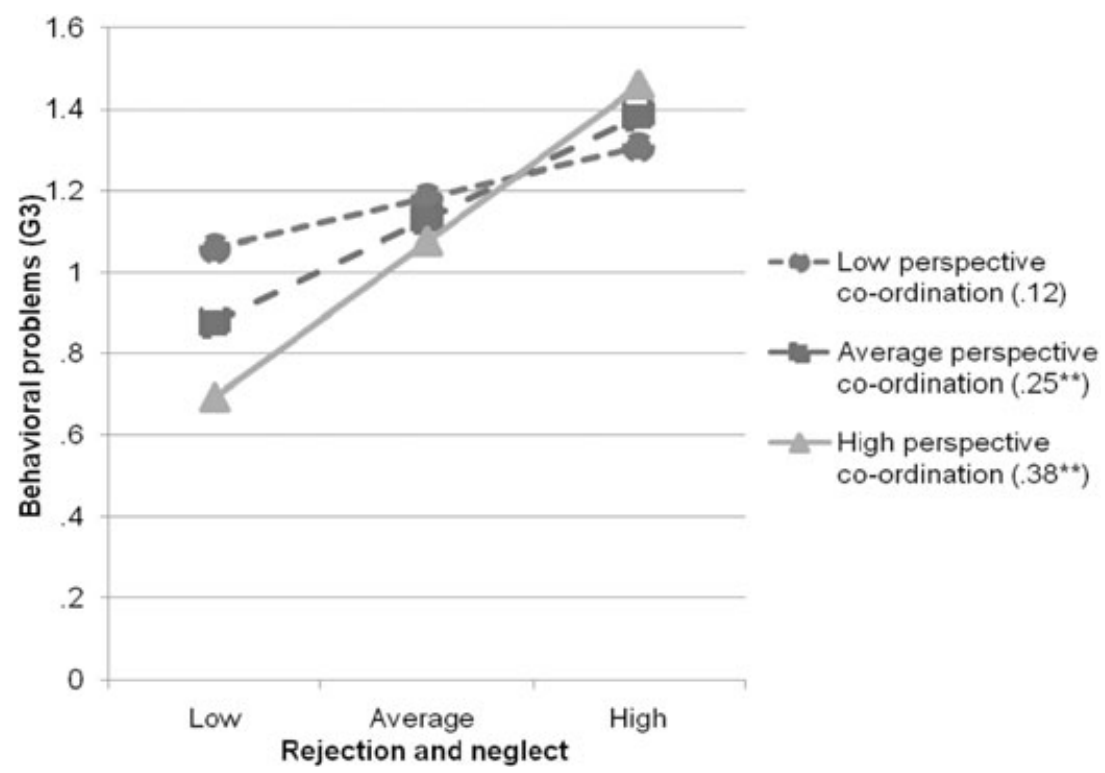

Figure 2. The Relation between Peer Rejection and Neglect and Prospective Behavioral Problems as a Function of Interpersonal Perspective Co-ordination.

Note: G3 = grade 3 . Numbers in parentheses are $\beta$ values for slopes $(* * p<.01)$. Slope was significantly different from zero for average $(t[98]=3.40, p<.01)$ and high $(t[98]=3.63, p<.01)$.

co-ordination may be particularly sensitive to or aware of their social status and retaliate with more aggressive, disruptive, and unco-operative behaviors compared to children who lack this awareness or 'optimistic bias' (see Rudolph \& Clarke, 2001).

Emotional Problems. As shown in Table 3, the regression equations examining the effects of each domain of social-cognitive competence (interpretive understanding and perspective co-ordination) and peer rejection and neglect on concurrent and prospective levels of emotional problems, controlling for baseline problems and word count, were both significant. These equations explained 45 and 37 percent of the variance in concurrent and prospective levels of emotional problems, respectively. Findings were similar, with the exception that perspective word count was marginally associated with higher levels of prospective but not concurrent emotional problems. As with behavioral problems, this suggests that verbal fluency may play a role in children's ability to manage sadness, anxiety, and introversion. Peer rejection and neglect were associated with significantly more emotional problems, both concurrently and over time. The main effects of perspective co-ordination and also interpretive understanding were not significant. Perspective co-ordination (but not interpretive understanding) moderated the effect of rejection and neglect on both concurrent and prospective levels of emotional problems. As with behavioral problems, peer rejection and neglect contributed to more concurrent and prospective emotional problems for children who showed average or high (but not low) levels of perspective co-ordination (see Figures 3 and 4), with more robust effects for prospective emotional problems relative to concurrent 
16 Wendy L. G. Hoglund, Christopher E. Lalonde and Bonnie J. Leadbeater

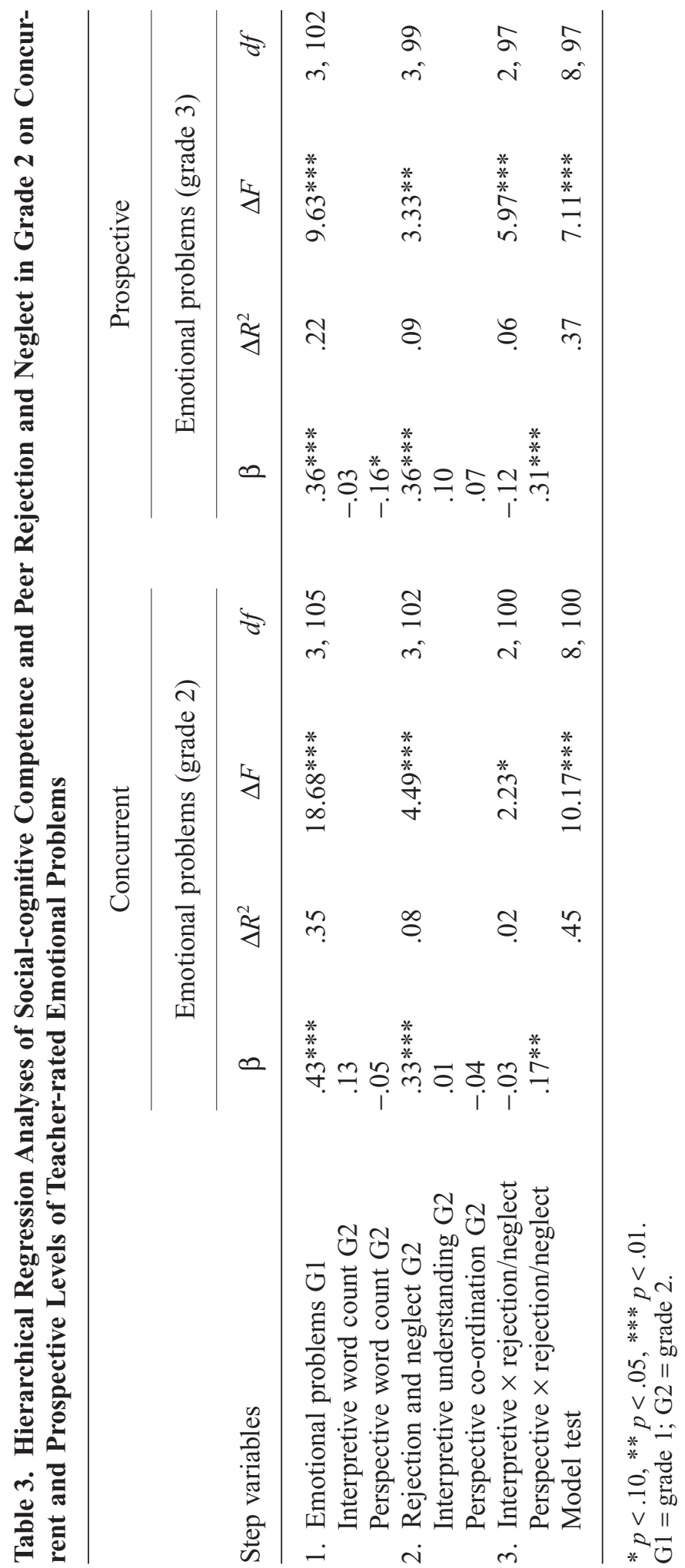




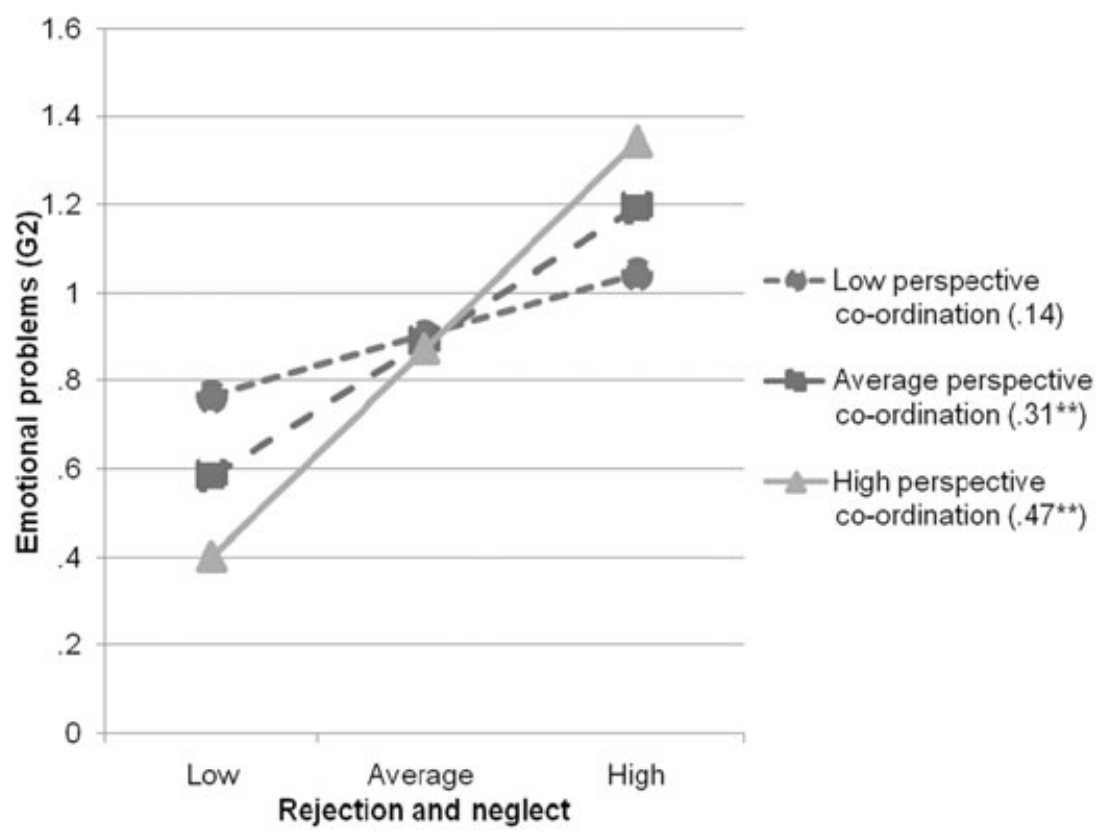

Figure 3. The Relation between Peer Rejection and Neglect and Concurrent Emotional Problems as a Function of Interpersonal Perspective Co-ordination.

Note: $\mathrm{G} 2=$ grade 2 . Numbers in parentheses are $\beta$ values for slopes $(* * p<.01)$. Slope was significantly different from zero for average $(t[100)=3.74, p<.01)$ and high $(t[100]=4.11, p<.01)$ levels of interpersonal perspective co-ordination.

problems. These findings lend further support to the theory that more sophisticated perspective co-ordination skills may serve to intensify children's sadness, anxiety, and shyness for children who are rejected or neglected by their peers.

\section{Discussion}

This prospective, longitudinal study examined how individual differences in two dimensions of children's social-cognitive competence, cognitive interpretive understanding and interpersonal perspective co-ordination, related to behavioral and emotional problems and moderated the effect of peer rejection and neglect on these problems, concurrently and over time. Our study extends past research on socialcognitive processes and peer rejection and neglect by offering additional insight into how social cognitions can influence behavioral and emotional problems in the context of peer problems. Consistent with previous research (Bosacki \& Astington, 1999; Hughes \& Dunn, 1998), interpretive understanding and perspective co-ordination correlated positively and showed similar bivariate associations with peer rejection and neglect and behavioral and emotional problems. The moderate correlations between these two aspects of social-cognitive suggest that these cognitive-oriented and interpersonal-oriented abilities reflect similar but not overlapping constructs. Our findings further suggest that interpersonal perspective co-ordination may be more salient for children's behavioral and emotional problems than cognitive interpretive 


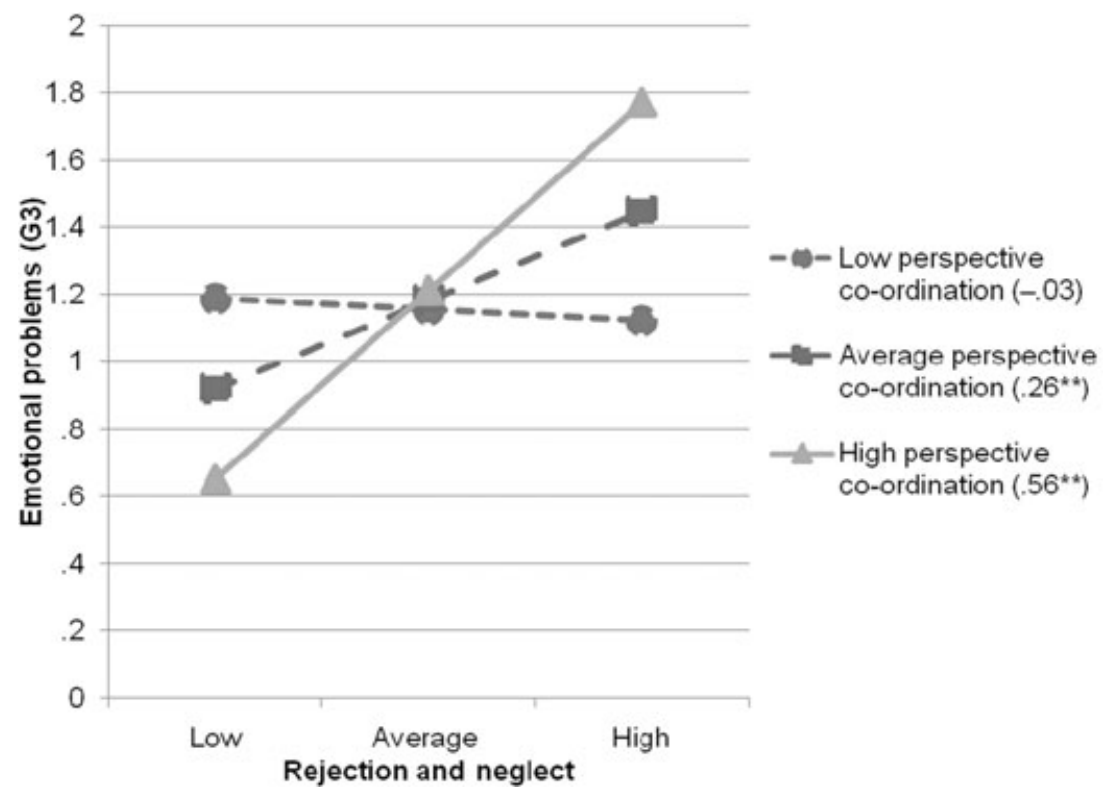

Figure 4. The Relation between Peer Rejection and Neglect and Prospective Emotional Problems as a Function of Interpersonal Perspective Co-ordination.

Note: $\mathrm{G} 3=$ grade 3 . Numbers in parentheses are $\beta$ values for slopes $(* * p<.01)$. Slope was significantly different from zero for average $(t[97]=2.94, p<.01)$ and high $(t[97]=4.49, p<.01)$ levels of interpersonal perspective co-ordination.

understanding, particularly in the context of peer problems. Although our findings suggest that social-cognitive competence generally enhances children's ability to regulate aggressive, disruptive behaviors and sadness, anxiety, and withdrawal, findings also challenge assumptions that skillful awareness of others' motives and feelings bestows consistent benefits for children experiencing peer rejection and neglect. Below we discuss the costs of peer rejection and neglect for behavioral and emotional problems and the potential benefits and also the costs that sophisticated socialcognitive abilities can confer in middle childhood.

Peer rejection and neglect have been identified as interpersonal stressors that mark risks for later problematic outcomes (Bierman, 2004; Newcomb et al., 1993). Such peer problems can limit children's opportunities to interact with prosocial peers, influence their expectations about future peer interactions, and affect the developmental course of behavioral and emotional problems. Consistent with this and other longitudinal evidence (Dodge et al., 2003; Ladd, 2006; Ladd \& Troop-Gordon, 2003; Rudolph et al., 1997), findings showed that peer rejection and neglect significantly increased risks for behavioral and emotional problems in both the short and the long term. The strength of these associations held after the stability in these problems was accounted for and was consistent across time and across behavioral and emotional problems. Peer rejection and neglect might forecast multiple forms of maladjustment because once children are marked for rejection and neglect, it sanctions the larger peer group to marginalize these children (Buhs \& Ladd, 2001). Such hurtful experiences likely contribute to risks for ongoing maladjustment because children's needs for acceptance and inclusion by the 
peer group are not met, becoming an impetus for the development of aggressive, disruptive behaviors or sadness, anxiety, and withdrawal. It is possible that rejection and neglect run concomitantly with both aggressive, disruptive behaviors and anxious, withdrawn behaviors, creating a risk-maladjustment-risk cycle. However, Ladd found that peer rejection evidenced greater stability across middle childhood than behavioral or emotional problems and found little support for a transactional model, suggesting that rejection is generally more predictive of later maladjustment than the reverse. Our findings further suggest that the short- and long-term costs of these peer problems for both behavioral and emotional problems depend in part on individual differences in interpersonal perspective co-ordination abilities.

\section{Interpersonal Perspective Co-ordination}

Our findings converge with theory on interpersonal perspective co-ordination (Selman, $1980,2003)$ in documenting that individual differences in the capacity to understand others' emotions and motives in social interactions relates to children's behavioral and emotional adjustment. Children who can adeptly anticipate how peers might perceive and respond to a given social interaction are able to co-ordinate differing perspectives and generate resolutions to conflicts that benefit the relationship in the long term. Consistent with past interpersonal perspective research (Bosacki \& Astington, 1999; Dunn \& Cutting, 1999; Hoglund \& Leadbeater, 2007; Leadbeater et al., 2006; Schultz et al., 2004; Yeates et al., 1991), more skillful interpersonal perspective co-ordination (awareness of others' emotional states and motives) was correlated with fewer behavioral problems, concurrently and over time, and with emotional problems, concurrently but not prospectively. Children who are aware of others' emotions and motives may be better able to regulate their own behavioral and emotional responses in the short term, but over time, feelings of sadness, anxiety, and withdrawal may become more independent of competent perspective co-ordination abilities. Over time, emotionally vulnerable children might be presented with more occasions to interact with familiar and unfamiliar prosocial peers than aggressive children because they are perceived as safer playmates and yield to peers' demands more often (Adalbjarnardottir, 1995; Erdley \& Asher, 1996; Yeates et al., 1991). These interactions might provide depressed, anxious, and withdrawn children with opportunities to gain insight into others' emotions and motives.

After the stability in behavioral and emotional problems was controlled, perspective co-ordination contributed independently and significantly to behavioral problems only (and only at the trend level for prospective problems). Aggressive, disruptive children may have particular difficulty attending to multiple points of view in conflict situations and may be particularly likely to focus on their own singular perspective, possibly because they exaggerate others' aggression or perceive others' ambiguous motives as hostile (Dodge et al., 2003; Erdley \& Asher, 1996; Hoglund \& Leadbeater, 2007; Rudolph \& Clarke, 2001). Programmatic efforts directed at enhancing aggressive children's cognitive flexibility are needed. For instance, training that focuses on these children's ability to attend to viewpoints outside of the immediate interaction or relationship may help them suspend beliefs of others as malicious and restrain inclinations to use aggression as a way to deal with threats (Crick \& Dodge, 1994; Erdley \& Asher, 1996).

Social-cognitively competent children are thought to be less distracted by short-term problems and able to skillfully negotiate interpersonal conflicts in ways that preserve 
relationships in the long term (Selman, 2003). However, chronic peer problems may undermine consistency in children's use of age-appropriate perspective co-ordination skills. Individual differences in perspective co-ordination were expected to moderate the relations between peer rejection and neglect and children's concurrent and prospective problems. Consistent with some previous social-cognitive research (Cutting \& Dunn, 2002; Rudolph \& Clarke, 2001; Rudolph et al., 1997), our findings suggest that proficiency in balancing multiple emotions and motives in conflict situations can actually elevate children's sensitivity to peer problems and strain their ability to adjust well in both the short and the long term. Specifically, greater peer rejection and neglect contributed to more behavioral and emotional problems, both concurrently and over one year, particularly for children who showed average and high levels of perspectiveco-ordination abilities. Similarly, a reexamination of the slope estimates presented in Figures 1-4 reveals that (as expected) skillful perspective co-ordination relates consistently to lower levels of behavioral and emotional problems at low levels of peer rejection and neglect, but is associated with some increases in behavioral problems and more prominent gains in emotional problems at high levels of rejection and neglect. This suggests that social-cognitively competent children are particularly sensitive to these peer problems and may more often respond with emotional distress than with aggression. It is also possible that less competent children can maintain an 'optimistic bias' about their acceptance by peers because of a limited cognitive understanding of rejection or neglect by peers (Rudolph \& Clarke, 2001).

Cutting and Dunn (2002) found that preschool children competent in theory of mind and emotional awareness tasks showed greater sensitivity to teacher criticism in grade 1 than children with a poorer understanding of others' cognitions and emotions. A heightened sensitivity to peer rejection and neglect for children competent in recognizing others' emotional and motivational states converges with theory on empathy (Eisenberg, 2003). Empathy involves the accurate recognition of others' emotion signals and a vicarious experience of the perceived emotion, and also requires children to differentiate between their own and others' emotions. When empathic responses are self- rather than other-focused, they can result in feelings of personal distress that include discomfort, anxiety, and so forth that are more characteristic of sympathy than empathy. In line with this, sophistication in detecting others' emotions may come at a cost for rejected or neglected children if their empathic responses are overly selffocused or more sympathetic than empathic. These risks may be concomitant for aggressive and emotionally distressed children and also emerge over time, especially for emotionally distressed children, when accompanied by chronic peer problems (Dodge et al., 2003; Ladd, 2006).

Consistent with other longitudinal evidence on peer rejection and emotional problems (Ladd, 2006), the costs of rejection and neglect may intensify over time for depressed, anxious, and withdrawn children who are social-cognitively skilled because such painful peer experiences slowly feed self-focused cognitions that exaggerate their poor social standing in the peer group. These children may ruminate persistently over possible adverse peer interactions and become overly apprehensive or distrustful of peers, isolating these children from the peer group even further (Ladd \& TroopGordon, 2003; Pomerantz \& Rudolph, 2003; Rudolph \& Clarke, 2001). Emotionally vulnerable children may come to believe that their poor peer status is uncontrollable due to their own personal inadequacies and that they do not have the power to alter the course of future interactions, elevating risks for ongoing emotional distress (Graham \& Juvonen, 1998). Over time, these children might behave in ways that seemingly invite 
peer rejection or neglect, such as submitting easily to peers' social demands and acquiescing to unfair game rules created by unkind peers, prompting feelings of anxiety and worthlessness (Hodges \& Perry, 1999).

Similar to Ladd (2006), the influence of peer rejection and neglect on behavioral problems became somewhat weaker over time for aggressive, disruptive children who showed a more sophisticated perspective co-ordination. Peer rejection and neglect might spark negative cognitions among aggressive children and early aggression might elevate risks for ongoing behavioral problems (Ladd, 2006; Ladd \& Troop-Gordon, 2003). Aggressive children might also enact preemptive or retaliatory aggression to protect themselves from peer hostilities and become less accommodating and more dominant or aggressive in interpersonal interactions, for example by controlling valued resources with peers to maintain a sense of power (Dodge et al., 2003; Hodges \& Perry, 1999). It is also possible that more sophisticated social-cognitive abilities enable children to limit reactions to peer problems because they become more attuned to social conventions that condemn aggression and transform their feelings of anger into internalized distress. Future research that examines how individual differences in perspective co-ordination relate over time to negative self- and peer-views (Pomerantz \& Rudolph, 2003), self- and other-blaming attributions (Graham \& Juvonen, 1998), and hypervigilance to hostile social cues (Dodge et al., 2003) could extend the understanding of the role that these social cognitions play in increasing sensitivity to peer rejection and neglect.

\section{Cognitive Interpretive Understanding}

Our findings also correspond with theory on interpretive understanding (Chandler \& Lalonde, 1996) in documenting that individual differences in appreciating that the same reality can be differentially interpreted and misinterpreted by different people relates to the extent to which children adjust behaviorally and emotionally. Children who can understand that others might hold unique and legitimate interpretations of the exact same social interaction may be able to anticipate and reflect on differing perspectives in ambiguous social interactions. On the basis of this and theory of mind research (Cassidy, Werner, Rourke, \& Zubernis, 2003; Jenkins \& Astington, 2000; Slaughter et al., 2002; Watson et al., 1999), we expected that interpretive understanding of others' cognitions would contribute to fewer behavioral and emotional problems, concurrently and prospectively, and that individual differences in these cognitions would also moderate the relation between peer rejection and neglect and these problems. Interpretive understanding was associated bivariately with moderately lower levels of behavioral and emotional problems both concurrently and over time. Although the majority of theory of mind research has focused on how cognitive understanding of mental states, predominately false belief understanding, relates to social adjustment, our findings extend this line of research in showing that interpretive understanding is also associated with fewer behavioral and emotional problems. Sophistication in interpretive understanding may enhance children's ability to cooperate with others, conform to social rules, and limit aggressive, disruptive or anxious, withdrawn behaviors because their cognitive flexibility enables them to understand the ambiguity in their daily social encounters.

Nonetheless, associations between interpretive understanding and behavioral and emotional problems were not significant in the regression equations. Attention to others' emotional and motivational states, as tapped by perspective co-ordination, may 
be a more robust contributor of children's behavioral and emotional problems than the cognitive appreciation of multiple interpretations of ambiguous stimuli and may partially explain the mixed findings for associations between theory of mind tasks and peer problems (Bosacki \& Astington, 1999; Kauklainen et al., 1999; Slaughter et al., 2002; Sutton et al., 1999). It is also possible that the social-cognitions' characteristic of interpretive understanding actually precede those reflected in perspective co-ordination such that a general appreciation that two people can hold unique beliefs of the same ambiguous stimuli is a necessary but insufficient condition for the ability to co-ordinate multiple perspectives in an interpersonal conflict. Unlike perspective co-ordination, sophistication in understanding others' cognitive interpretations did not moderate the effect of peer rejection or neglect on behavioral or emotional problems. It may be that cognitive appraisals of peer problems need to be attuned to the emotional and motivational states of others to affect children's behavioral and emotional problems in the context of peer rejection or neglect (Eisenberg, 2003; Lemerise \& Arsenio, 2000). The ICC and mean level of interpretive understanding were substantially higher than for perspective co-ordination, indicating decreased power to detect effects for interpretive understanding. Future studies need to consider the possible inter-dependence of children's cognitions within classrooms and the possibility that multilevel modeling may be appropriate for investigating changes in social cognitions over time.

More consistent and robust effects were found for perspective co-ordination, potentially because our assessment of perspective co-ordination tapped children's awareness of others' emotions and motives and was assessed in the context of hypothetical peer provocations. These vignettes may have increased children's attention to others' internal worlds. However, the main and interactive effects for perspective co-ordination were modest and the direction of the interactions was unexpected. Future studies are needed to assess how variations in both interpretive understanding and perspective co-ordination influence the relations between peer rejection and neglect and behavioral and emotional problems concurrently and over time. Assessments of both aspects of social-cognitive competence with larger samples of children that extend over longer periods of time may further clarify the hypotheses tested here. Our sample size may have limited our ability to detect more robust effects. Although findings for the word counts related to the social-cognitive constructs were inconsistent and did not moderate the effects of social-cognitive competence, our ability to make substantive claims related to children's cognitive or verbal ability is limited as we did not include a standardized assessment of cognitive or verbal ability.

Social-cognitive studies that also include peer ratings of rejection and neglect are needed. Our assessment of rejection and neglect was limited by reliance on a two-item teacher report rather than the generally preferred peer assessments. Nonetheless, grade 2 teachers who reported on rejection and neglect were not the same as teachers who reported on children's behavioral and emotional problems in grades 1 and 3 . In addition, other research using the same teacher-report measure of peer rejection and neglect has reported adequate reliability (Rudolph et al., 1997). When analysed separately, there was a high concordance for the effects of rejection and neglect, suggesting that teachers viewed these as overlapping phenomena; peer assessments may yield more clearly distinct phenomena that relate differentially to behavioral and emotional problems. Studies that capture the duration and frequency of peer rejection and neglect over time, as reported by peers and teachers, could further explicate the complicated relations among social cognitions, peer problems, and behavioral and emotional 
problems found here and elsewhere (Dodge et al., 2003; Ladd \& Troop-Gordon, 2003; Rudolph \& Clarke, 2001).

General support was found for theoretically guided programs aimed at enhancing children's peer relationships, ability to balance multiple opposing perspectives, and skills resolving interpersonal conflicts. Nonetheless, our findings also urge caution in programmatic efforts directed at only enhancing social-cognitive competence for rejected or neglected children. How cognitive schemas about others' internal worlds guide children's beliefs about their positioning in the peer world and strategies to manage interpersonal conflicts in ways that accommodate the needs of both the self and others requires further investigation. Identification of the cues that socialcognitively skilled children attend to and how these cues influence their adjustment in the context of peer relationship problems is necessary to inform the generation of developmentally sensitive prevention programs directed at the prevention of peer rejection and neglect and behavioral and emotional problems.

\section{References}

Adalbjarnardottir, S. (1995). How schoolchildren propose to negotiate: The role of social withdrawal, social anxiety, and locus of control. Child Development, 66, 1739-1751.

Aiken, L. S., \& West, S. G. (1991). Multiple regression: Testing and interpreting interactions. Newbury Park, CA: Sage Publications.

Astington, J. W., \& Jenkins, J. M. (1995). Theory of mind development and social understanding. Cognition and Emotion, 9, 151-165.

Badeness, L. V., Estevan, R. A. C., \& Bacete, F. J. G. (2000). Theory of mind and peer rejection at school. Social Development, 9, 271-283.

Bierman, K. L. (2004). Peer rejections: Developmental processes and intervention strategies. New York: Guilford Press.

Bosacki, S., \& Astington, J. W. (1999). Theory of mind in preadolescence: Relations between social understanding and social competence. Social Development, 8, 237-255.

Buhs, E. S., \& Ladd, G. W. (2001). Peer rejection as an antecedent of young children's school adjustment: An examination of mediating processes. Developmental Psychology, 37, 550560.

Caldwell, C. B., \& Pianta, R. C. (1991). A measure of young children's problem and competent behaviors: The early school behavior scale. Journal of Psychoeducational Assessment, 9, $32-44$.

Carpendale, J. I., \& Chandler, M. J. (1996). On the distinction between false belief understanding and subscribing to an interpretive theory of mind. Child Development, 67, 1686-1706.

Cassidy, K. W., Werner, R. S., Rourke, M., Zubernis, L. S., \& Balaraman, G. (2003). The relationship between psychological understanding and positive social behaviors. Social Development, 12, 198-221.

Chandler, M., \& Lalonde, C. (1996). Shifting to an interpretive theory of mind: 5- to 7-yearolds' changing conceptions of mental life. In A. Sameroff, \& M. Haith (Eds.), Five to seven year shift: The age of reason and responsibility (pp. 111-139). Chicago, IL: University of Chicago Press.

Crick, N. R., \& Dodge, K. A. (1994). A review and reformulation of social informationprocessing mechanisms in children's social adjustment. Psychological Bulletin, 115, 74-101.

Cutting, A. L., \& Dunn, J. (2002). The cost of understanding other people: Social cognition predicts young children's sensitivity to criticism. Journal of Child Psychology \& Psychiatry, $43,849-860$.

Dekovic, M., \& Gerris, J. R. M. (1994). Developmental analysis of social cognitive and behavioral differences between popular and rejected children. Journal of Applied Developmental Psychology, 15, 367-386.

Dodge, K. A., Lansford, J. E., Burks, V. S., Bates, J. E., Pettit, G. S., Fontaine, R., et al. (2003). Peer rejection and social information-processing factors in the development of aggressive behavior problems in children. Child Development, 74, 374-393. 


\section{Wendy L. G. Hoglund, Christopher E. Lalonde and Bonnie J. Leadbeater}

Dunn, J., \& Cutting, A. (1999). Understanding others, and individual differences in friendship interactions in young children. Social Development, 8, 201-219.

Eisenberg, N. (2003). Prosocial behavior, empathy, and sympathy. In M. H. Bornstein, \& L. Davidson (Eds.), Well-being: Positive development across the life course (pp. 253-265). Mahwah, NJ: Lawrence Erlbaum Associates.

Erdley, C., \& Asher, S. (1996). Children's social goals and self-efficacy perceptions as influences on their responses to ambiguous provocation. Child Development, 67, 1329-1344.

Fitzgerald, D. P., \& White, K. J. (2003). Linking children's social worlds: Perspective-taking in parent-child and peer contexts. Social Behavior and Personality, 31, 509-522.

Gazelle, H. (2006). Class climate moderates peer relations and emotional adjustment in children with an early history of anxious solitude: A child $\times$ environment model. Developmental Psychology, 42, 1179-1192.

Graham, S., \& Juvonen, J. (1998). Self-blame and peer victimization in middle school: An attributional analysis. Developmental Psychology, 34, 587-599.

Hodges, E. V., \& Perry, D. G. (1999). Personal and interpersonal antecedents and consequences of victimization by peers. Journal of Personality and Social Psychology, 76, 677-685.

Hoglund, W. L., \& Leadbeater, B. J. (2007). Managing threat: Do social-cognitive errors and skills mediate the links between peer victimization and adjustment problems in late childhood? Journal of Research on Adolescence, 17, 525-540.

Hughes, C., \& Dunn, J. (1998). Understanding mind and emotion: Longitudinal associations with mental-state talk between young friends. Developmental Psychology, 34, 1026-1037.

Jenkins, J. M., \& Astington, J. W. (2000). Theory of mind and social behavior: Causal models tested in a longitudinal study. Merrill-Palmer Quarterly, 46, 203-220.

Kauklainen, A., Björkqvist, K., Lagerspetz, K., Österman, K., Salmivalli, C., Rothberg, S., et al. (1999). The relationships between social intelligence, empathy, and three types of aggression. Aggressive Behavior, 25, 81-89.

Ladd, G. (2006). Peer rejection, aggressive or withdrawn behavior, and psychological maladjustment from ages 5 to 12: An examination of four predictive models. Child Development, $77,822-846$.

Ladd, G., \& Troop-Gordon, W. (2003). The role of chronic peer difficulties in the development of children's psychological adjustment problems. Child Development, 74, 1344-1367.

LaFontana, K. M., \& Cillessen, A. H. N. (2002). Children's perceptions of popular and unpopular peers: A multimethod assessment. Developmental Psychology, 38, 635-647.

Lalonde, C. E., \& Chandler, M. J. (2002). Children's understanding of interpretation. New Ideas in Psychology, 20, 163-198.

Leadbeater, B. J., Ohan, J. L., \& Hoglund, W. L. (2006). How children's justifications of the 'best thing to do' in peer conflicts relate to their emotional and behavioral problems in early elementary school. Merrill-Palmer Quarterly, 52, 721-754.

Lemerise, E. A., \& Arsenio, W. F. (2000). An integrated model of emotion processes and cognition in social information processing. Child Development, 71, 107-111.

Mostow, A., Izard, C. E., Fine, S., \& Trentacosta, C. J. (2002). Modelling emotional, cognitive, and behavioral predictors of peer acceptance. Child Development, 73, 1775-1787.

Newcomb, A. F., Bukowski, W. M., \& Pattee, L. (1993). Children's peer relations: A metaanalytic review of popular, rejected, neglected, controversial, and average sociometric status. Psychological Bulletin, 113, 99-128.

Piaget, J. (1965). The moral judgment of the child. New York: Free Press.

Pillow, B. H., \& Henrichon, A. J. (1996). There's more to the picture than meets the eye: Young children's difficulty understanding biased interpretation. Child Development, 67, 803-819.

Pomerantz, E. M., \& Rudolph, K. D. (2003). What ensues from emotional distress? Implications for competence estimation. Child Development, 74, 329-345.

Price, R. (1953). Droodles. New York: Simon \& Schuster.

Raver, C., \& Leadbeater, B. J. (1993). The problem of the other in research on theory of mind and social development. Human Development, 36, 350-362.

Rudolph, K., Hammen, C., \& Burge, D. (1997). A cognitive-interpersonal approach to depressive symptoms in preadolescent children. Journal of Abnormal Child Psychology, 25, 33-45.

Rudolph, K. D., \& Clarke, A. G. (2001). Conceptions of relationships in children with depressive and aggressive symptoms: Social cognitive distortion or reality? Journal of Abnormal Child Psychology, 29, 41-56. 
Schultz, L. H., Selman, R. L., \& LaRusso, M. D. (2004). The assessment of psychosocial maturity in children and adolescents: Implications for the evaluation of school-based character education programs. Journal of Research in Character Education, 1, 67-87.

Selman, R. L. (1980). The growth of interpersonal understanding: Clinical and developmental analyses. New York: Academic Press.

Selman, R. L. (2003). The promotion of social awareness: Powerful lessons from the partnership of developmental theory and classroom practice. New York: Russell Sage Foundation.

Slaughter, V., Dennis, M. J., \& Pritchard, M. (2002). Theory of mind and peer acceptance in preschool children. British Journal of Developmental Psychology, 20, 545-564.

Sutton, J., Smith, P., \& Swettenham, J. (1999). Social cognition and bullying: Social inadequacy or skilled manipulation? British Journal of Developmental Psychology, 17, 435-450.

Watson, A. C., Nixon, C. L., Wilson, A., \& Capage, L. (1999). Social interaction skills and theory of mind in young children. Developmental Psychology, 35, 386-391.

Yeates, K. O., Schultz, L. H., \& Selman, R. L. (1991). The development of interpersonal negotiation strategies in thought and action: A social-cognitive link to behavioral adjustment and social status. Merrill-Palmer Quarterly, 37, 369-405.

\section{Acknowledgments}

This research was funded by grants from the Social Sciences and Humanities Research Council of Canada, the Canadian Institute of Health Research, and the B.C. Ministry of Education awarded to the third author. We thank all of the children, parents, and teachers who participated in this research. An earlier version of this article was presented at the 35th annual Jean Piaget Society meeting in Vancouver, British Columbia (June 2005). Wendy Hoglund is now at New York University.

\section{Appendix A: Cognitive Interpretive Understanding Task}

The 'Ship-Witch' droodle

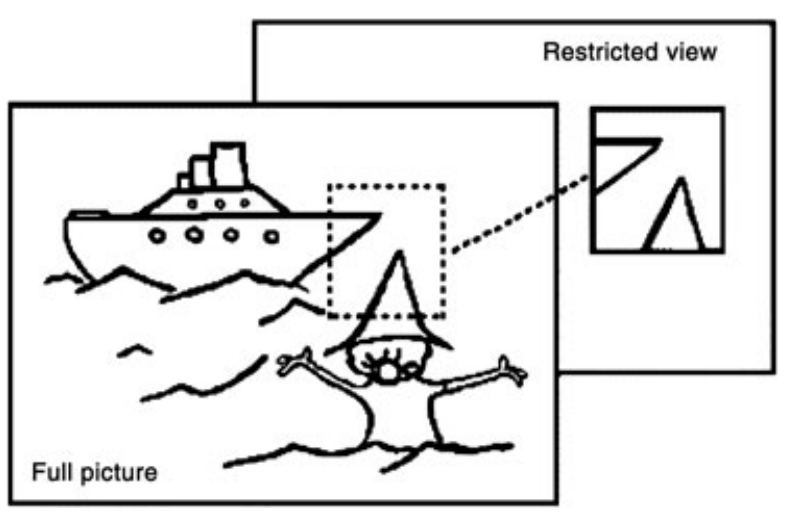

\section{Appendix B: Interpersonal Perspective Co-ordination Vignettes}

\section{Erin and Kelly Story}

'Erin, a new kid in the class, doesn't have friends yet. Kelly is friends with most of the other kids and doesn't like Erin. Every time Erin tries to make friends with the other kids, Kelly teases Erin about the way Erin looks. One day Kelly was playing with some kids on the playground. When Erin asks to play with them, Kelly says "No! We aren't playing with you.", 


\section{Chris and Taylor Story}

'Chris is picked on by some of the kids at school and especially by Taylor. Sometimes Taylor pushes Chris when they are on the playground. One day, Chris and a friend are playing with Chris's new basketball. Taylor sees the basketball and wants to play too. Taylor starts pushing and hitting Chris. Some of the other kids are standing around watching them.' 